\title{
"La Santa causa de la Antilla hermosa encuentra en Chile un entusiasmo ardiente": El movimiento de solidaridad hacia el independentismo cubano durante 1895
}

\author{
The Holy Cause of the beautiful Antilles finds in Chile an ardent \\ enthusiasm": The movement of solidarity towards Cuban \\ independence during 1895
}

Mario Vega Henríquez*

\section{RESUMEN}

El presente trabajo aborda la recepción de la guerra de IndePalabras clave: pendencia cubana de 1895 en Chile, a partir de la estrategia del Independencia Partido Revolucionario Cubano (PRC), de implementar vínculos de activa solidaridad hacia su causa mediante la visita de delegados a diversos países de la región, con la intención de presionar a sus respectivos gobiernos para lograr el reconocimiento de la condición de beligerantes de los insurgentes. Tal de Cuba, Arístides Agüero, Partido Revolucionario Cubano, política exterior de Chile. fue el caso de la presencia de Arístides Agüero en Chile quien, durante 1895, fue recibido por diversas organizaciones populares que adhirieron a su causa, tensionando la posición de neutralidad que el gobierno de Jorge Montt había definido, así como la posición vigilante de la influyente colonia española presente en el país. Lo anterior será analizado a partir del examen de prensa de la época, interpretando las representaciones discursivas construidas sobre este conflicto, con especial hincapié en los argumentos esgrimidos tanto por los partidarios como por los detractores del proceso de emancipación en las Antillas Mayores.

\footnotetext{
* Chileno. Magíster en Historia, Universidad de Chile; magíster en Educación, Universidad Academia de Humanismo Cristiano; estudiante del programa de Doctorado en Estudios Latinoamericanos, Facultad de Filosofía y Humanidades, Universidad de Chile. E-mail: mariovega@ug.uchile.cl
} 


\begin{abstract}
This paper describes the Chilean reaction regarding the Cuban War of Independence of 1895. Particularly on the Cuban Revolutionary Party (PRC)'s strategy to implement links of active solidarity with its cause through delegates' visits to various countries in the region to pressure their respective governments to recognize the insurgents' belligerent status. Such was the case of Arístides Agüero's presence in Chile. During 1895, he was received by various popular organizations supporting his cause, thus putting pressure on the neutral position that Jorge Montt's government had defined, adding to the vigilant status of the country's influential Spanish colony. We will analyze this subject by examining the press of the time, interpreting the discursive representations built on this conflict, emphasizing the arguments put forward by both supporters and detractors of the Greater Antilles' emancipation process.
\end{abstract} Keywords: Cuban Independence, Arístides Agüero, Cuban Revolutionary Party, foreign policy of Chile. 
La coyuntura finisecular del XIX representó el apogeo del imperialismo europeo en todo el mundo, en especial por parte de las grandes potencias europeas que experimentaron "una nueva fase de la expansión nacional" (Hobsbawm, 2009: 68), etapa signada por la hegemonía de la burguesía. Esta fue la época en la que sus intereses económicos y políticos trascendieron los límites del continente, haciéndose presentes a escala global. España, por su parte, a esas alturas en condición de potencia de segundo orden, se debatió en las vicisitudes políticas de una inestable monarquía parlamentaria, pugnando por mantener el control de los vestigios de su imperio colonial, especialmente en Cuba y Puerto Rico, territorios en donde se acrecentó la influencia política y económica de los Estados Unidos, inspirada en la Doctrina Monroe, así como el surgimiento de la insurgencia independentista. Con todo, estos aspectos se tornaron una permanente amenaza sobre los intereses peninsulares (Ansaldi y Giordano, 2016).

En contrapartida, en América Latina los regímenes impulsores del "orden y el progreso" señalaron "la edad de oro del proyecto oligárquico" (Carmagnani, 1984: 98), fundado en la conexión entre las elites locales y los intereses imperialistas externos desde la provisión de materias primas a las economías industrializadas, cuyo marco fue completado por una participación política limitada del resto de la sociedad. Chile, por su parte, no fue la excepción y su modelo de relación entre los partidos, la sociedad y el Estado estuvo fuertemente hegemonizado por el poder de la oligarquía, según las interpretaciones sostenidas por la historiografía. Esta oligarquía nacional manifestó una continua ausencia de preocupaciones sociales y carencia de una adecuada visión del contexto internacional con el que se vinculaba el país, al tiempo de estar desprovista de perspectivas que observaran las hondas transformaciones que estaban operando en las estructuras económicas y sociales, a saber, la reorientación de los antiguos propietarios mineros, el surgimiento de una burguesía industrial y la resistencia de la oligarquía terrateniente a su modernización (Carmagnani, 1984).

En 1890, los trabajadores organizados realizaron una huelga general (Grez, 2000), que significó un punto de inflexión del gradual fortalecimiento de las asociaciones obreras, en un camino no exento de dificultades y de contradicciones. El mundo social, que por ese entonces aún no contaba con protagonismo histórico relevante, pasó a ser 
gradualmente un elemento de consideración en el panorama político nacional. Dentro de este mundo, dos fueron las grandes corrientes que fortalecieron su representación social. Una de esas orientaciones fue el mutualismo, que adhería a los planteamientos reformistas evolutivos y que tuvo un estrecho vínculo con el programa del Partido Demócrata. La otra fue la de las mancomúnales y las sociedades de resistencia, decididamente anticapitalistas, marcadas por una lógica de combate y enfrentamiento al sistema, proclives a la incipiente izquierda. Todo ello se dio en medio de un debate político que tempranamente fue retomado durante el gobierno de Jorge Montt. La división entre dos tendencias de la época, clericalismo y laicismo, volvió a ser punto de discordia, alcanzando uno de sus niveles más álgidos tras la determinación del arzobispo de Santiago, Mariano Casanova, quien "prohibió la lectura del diario radical La Ley, bajo pena de excomunión" (Subercaseaux, 1994: 96). Subyacía en esta determinación el choque entre una cultura liberal, racionalista y laica, claramente modernizadora, contra el clericalismo que se resistía a perder su influencia en la sociedad. Los círculos intelectuales, a su vez, se hicieron receptivos por esos años a la fuerte influencia del modernismo (Subercaseaux, 1994) que permeó a las corrientes de la cultura nacional en distinta medida. Recordemos la significativa presencia en nuestro país del poeta Rubén Darío, quien legó una importante herencia sobre nuestras letras. Sea que hablemos de las expresiones de la cultura religiosa o laica, en especial en la literatura, el influjo de renovación y, con ello, la referencia a nuevos paradigmas estéticos e ideológicos es insoslayable como componente de la cultura en Chile a fines del siglo XIX.

El Chile de 1895, año en el que se centra nuestro estudio, fue escenario de un intenso debate político y una constante circulación de ideas. Esta agitada contingencia tuvo en la prensa escrita un espacio privilegiado, toda vez que circulaban en el territorio cerca de trescientos periódicos (Subercaseaux, 1994). A pesar de ello, estamos hablando de una discusión limitada por un hecho esencial como era el analfabetismo, que rondaba el 68\% de la población (Subercaseaux, 1994). Por lo tanto, a pesar de los esfuerzos llevados a cabo por organizaciones obreras, la disputa política se restringía principalmente a la elite. Esta condición reforzó en los líderes populares la conciencia acerca de la importancia de intervenir sobre los espacios públicos con sus demandas. 
En estos años, Chile era considerado un actor de relevancia en la región. Las exportaciones salitreras generaron vínculos con nuevos mercados, profundizando las relaciones con otros países a través del intercambio comercial. Ante sus antiguos oponentes de la Guerra del Pacifico, la diplomacia chilena fue paulatinamente normalizando sus contactos, en un camino lento y gradual. Con Argentina, en cambio, las diferencias no fueron saldadas del todo, ya que, a los litigios pendientes, se sumó el de la denominada Puna de Atacama (Castedo, 1999), mientras que, con los Estados Unidos, los efectos del "incidente del Baltimore" (1891) habían fortalecido la desconfianza hacia la política de Washington en la región. Por su parte, los vínculos con Cuba se remontan a mediados del siglo XIX cuando, en el marco de la Guerra contra España, de 1865, el gobierno de Chile envió a Benjamín Vicuña Mackenna, en calidad de agente confidencial, a Estados Unidos. El viaje tuvo como fin apoyar económicamente los incipientes esfuerzos de los insurgentes isleños como expresión de un común espíritu americanista. En tal perspectiva, la historiografía sobre las relaciones chileno-cubanas es limitada respecto de la cantidad de investigaciones disponibles, especialmente las referidas a la segunda mitad del siglo XIX. En estos trabajos, no obstante, se plantean en general concordancias respecto del significado que los actos de solidaridad y visitas de delegados del independentismo antillano tuvo sobre los países de la región, así como sobre la evolución temporal que estos procesos experimentaron. En tal sentido, para José M. Pozo, se registró una evolución en las relaciones con la isla, pues, en esta época, "adquieren mucha relevancia las relaciones extraestatales, desde el momento en que importantes sectores políticos del liberalismo y radicalismo chileno, y de asociaciones de militantes latinoamericanistas, entablan una sentida adhesión con los líderes proindependentistas cubanos" (Pozo, 1998: 345).

En una línea similar, Ricardo López plantea que este proceso representó

"la transición entre un americanismo solidario preminente dentro de la cultura política chilena en el contexto de las intervenciones europeas sobre Hispanoamérica de inicios de la segunda mitad del siglo XIX, hacia una perspectiva política cuyo centro sería el propio país, y (...) una renuncia explícita al americanismo" (López, 2015: 55). 
Desde la perspectiva del contexto e implicancias de la construcción de vínculos de adhesión al independentismo, así como sus limitados alcances en el ámbito de los gobiernos de la región, Claudio A. Gallegos plantea que la búsqueda de solidaridad hacia su causa representó una estrategia deliberada por parte del Partido Revolucionario $\mathrm{Cu}$ bano (PRC), en la idea de "expandir la guerra más allá del campo de batalla: se espera una guerra desde dentro y fuera de la isla.(...) en la Revolución de 1895 habría un plan ideado para llevar a cabo nuevas relaciones con el resto de los estados" (Gallegos, 2020: 2). Sin embargo, los infructuosos resultados de esta estrategia representaron para el historiador cubano Sergio Guerra Vilaboy "La falta de reconocimiento gubernamental por parte de los países latinoamericanos durante la Guerra de 1895 (...) [y] facilitaron los planes de Estados Unidos para intervenir en el conflicto hispano-cubano en 1898" (Guerra, 1993: 79).

Desde nuestra perspectiva, proponemos que, bajo las condiciones descritas, la estrategia del independentismo cubano de presionar al gobierno de Chile tuvo un carácter marcadamente estratégico. Para tal efecto, se activaron vínculos históricos entre ambas naciones, promoviendo la visita de ilustres representantes de la insurgencia y desplegándose una admirable y espontánea adhesión promovida por organizaciones populares hacia esta causa. Así, se logró abrir un debate que, reflejado a través de la prensa, buscó inducir a la autoridad a abandonar su actitud de prescindencia, haciendo incómoda la posición de neutralidad que el gobierno de Jorge Montt había definido en relación con el conflicto en la isla caribeña. De este modo, abordar la recepción y el debate político surgidos a partir del conflicto antillano, implica necesariamente recoger lo propuesto por Roger Chartier en torno a la idea de "disputas de representaciones" (Chartier, 1996: 48), en tanto idea nuclear de la historia cultural que se encarga de interpretar los símbolos y debates existentes en el pasado, con el fin de comprender la pugna social y política ahí confrontada al establecer que "no hay práctica ni estructura que no sea producida por las representaciones contradictorias enfrentadas, por las cuales los individuos y los grupos dan sentido al mundo que les es propio" (Chartier, 1996: 49).

Tales representaciones, elaboradas principalmente a partir de la palabra escrita, requieren, para abordar su análisis, de los recursos metodológicos propuestos por Michel Foucault. En primer lugar, para 
comprender la finalidad sociopolítica de los discursos levantados por parte de un activo movimiento de emancipación y solidaridad, dentro de una realidad concreta y en un espacio tiempo específico, es decir, "nos hace posible aprehenderlos como la imbricación entre un texto y un lugar social" (Maingueneau, 2005, citado en González y Martell-Gámez, 2013: 6). En otras palabras, utilizaremos su método de análisis transtextual, rescatando sus sentidos en tanto acción comunicativa, aludiendo a los conflictos y confrontaciones existentes en una sociedad. En tal sentido, nuestros objetivos trascienden un solo espacio nacional y, por lo tanto, se enfocan en lo que se ha denominado como "historia transnacional", o sea aquella que "hace referencia básicamente a la gran variedad de relaciones, lazos e interacciones que vinculan a personas e instituciones más allá de las fronteras de los Estados-nación" (Peyrou y Martykánová, 2014: 10), pero especialmente en el ámbito de aquello que incluso puede subvertir su control y "ordenamiento desafían[do] la soberanía del Estado y la hegemonía de las fronteras e ideologías nacionales" (Id. 14). Por su parte, para Caroline Nagel, además de su carácter alterno, los procesos transnacionales configuran una forma de "globalización desde abajo" (citada en Peyrou y Martykánová, 2014: 20), perspectiva con la cual situaremos este artículo.

\section{La política exterior de Chile y el contexto continental}

A fines del siglo XIX, la situación de Chile y de sus relaciones internacionales lo llevaron a definir un marco de búsqueda de armonía en su espacio próximo e inmediato, a la vez que de defensa de sus intereses. Por esos años surge un sentimiento de desconfianza hacia actores cada vez más protagónicos en el continente, como Estados Unidos, país con el que, a causa del "incidente del Baltimore" se habían producido momentos de tensión, que legaron huellas de recelo entre ambas naciones. A este complejo panorama se sumaron ciertos hechos y actitudes que mostraban la cada vez mayor injerencia norteamericana en la América Latina, particularmente a través de su influencia económica, la cual se tradujo en la incorporación de nuevos mercados consumidores, así como una creciente tutela política ejercida sobre estos. Este marco fue coherente con la denominada política del Big Stick (Barros, 1989), que pretendía consolidar la presencia norteamericana en el Caribe, pretensión que se unía a la llamada "Doctrina Monroe", con- 
figurando una actitud frente a la que los gobiernos del sur de América debían actuar con cautela.

Lo anterior hizo que el gobierno de la época asumiera un enfoque de relaciones exteriores con consideraciones que no necesariamente estaban del todo claras. Por un lado, se apoyaba en una extensa vocación americanista (López, 2015), sin embargo, ante la insurrección independentista cubana hubo, de parte de las autoridades, una actitud de cierta indiferencia. En tal sentido, más allá de aquello que fue expuesto públicamente, existen antecedentes fundados de la distancia que, en lo personal, el almirante Jorge Montt sentía hacia los Estados Unidos. Así, Hernán Ramírez Necochea, en una de sus más destacadas obras, Balmaceda y la Contrarrevolución de 1891 (2007), expone detalles respecto de ello en un documento confidencial del Foreing Office:

"Su Excelencia (...) comentó los discursos en el Senado de los Estados Unidos sobre la Doctrina Monroe, los cuales él dijo, indican claramente la idea de una eventual sujeción de todo el continente americano a los Estados Unidos y él me aseguró que Chile, Argentina, Brasil y Perú estaban ahora plenamente alertas a la necesidad de resistir cualquier avance aparentemente amistoso del Gobierno de los Estados Unidos" (Ramírez Necochea, 2007: 259).

Como se ha mencionado, hacia 1895, la posición de América Latina se había modificado sustancialmente, por cuanto "los estados se habían plegado a los dictados del Imperialismo” (Guerra, 1993: 68). Este hecho dificultó la posibilidad de una posición de independencia por parte de los países de la región frente a los conflictos surgidos nuevamente en Cuba. A su vez, el Cuarto Centenario del Descubrimiento de América, en 1892, generó condiciones para una atmósfera de acercamiento y de unidad hispanoamericana, oportunidad que fue hábilmente utilizada por la diplomacia española, con el fin de reforzar sus nexos diplomáticos con los países de la región. Una expresión de ello fue la mediación arbitral ejercida por la Reina María Cristina en diversos litigios limítrofes de carácter intrarregional, participación que condicionó las posibilidades de autonomía de su política exterior por parte de los Estados sometidos a este mecanismo, ante la eventualidad de ver perjudicados sus intereses a través de un fallo imprevisto. Frente a esto, la política de los EE.UU. fue percibida 
como una amenaza evidente, no solo sobre las Antillas Mayores, sino progresivamente sobre el conjunto del continente, siendo posible encontrar antecedentes de su política imperialista desde mediados del siglo XIX.

Estos factores complejizaron el juicio existente sobre la posición adoptada en la mencionada coyuntura por parte de los gobiernos de la región y, al mismo tiempo, aportaron matices que explican la adopción de una tímida neutralidad, la cual, sin embargo, logró efectivamente anular toda posibilidad de manifestación de una posición individual o común de los países del continente frente al proceso emancipador cubano.

Fuere el reciente acercamiento a la política hispana o la creciente desconfianza a la influencia estadounidense, la política definida por los Estados hizo que la pugna por disputar influencias sobre la opinión pública se hiciera más intensa y, para ello, fue indispensable que el independentismo diera vigencia y vitalidad a su demanda, mediante la visita de delegados que, en conexión directa con la ciudanía, presionaran para modificar la pusilánime actitud, como ellos describían, de sus gobernantes sudamericanos.

Por otra parte, se desconfió de la influencia de los EE.UU. y se estableció una política de neutralidad en el Caribe, no avizorándose todavía el momento en el que ambas posiciones podrían entrar eventualmente en colisión, tal como iba a ocurrir hacia 1898. Existía una gravitación política en el ámbito regional y las políticas de interlocución emprendidas se restringieron al ámbito de los conflictos limítrofes, mediante una estrategia ceñida a una prudencia excesiva.

\section{Recepción y solidaridad hacia la insurrección independentista cubana en Chile}

El 24 de febrero de 1895, día del inicio de los carnavales en la isla y tras la recepción de la expresión telegráfica "giros aceptados", comenzó la llamada Segunda Guerra de Independencia Cubana, liderada por José Martí junto a otros destacados líderes, como Antonio Maceo y Máximo Gómez. Este hito fue realizado mediante una sublevación que resultó exitosa en el Oriente del territorio, y que recoge la experiencia labrada en iniciativas bélicas previas, frustradas en sus expectativas de ruptura, como la Guerra de los Diez Años (1868-1878). Según el propio Martí, el 
conflicto iniciado en aquel año fue el resultado de la deliberación del PRC ante la posibilidad de una intervención de los EE.UU., en momentos en los que "el autonomismo había probado su inutilidad y no había otra vía que la guerra de independencia" (Estrada, 1987, como se citó en Soucy, 2014: 3).

Desde el primer momento en que se tuvieron noticias en Chile de la insurrección de los patriotas cubanos, las expresiones de solidaridad hacia esa causa no se hicieron esperar. La presencia de connotados intelectuales caribeños alentó tal reacción, unida a una gran comprensión de parte de las diversas organizaciones del mundo popular participantes. La algidez del conflicto hacia mediados de 1895, reproducida por los reportes de prensa, contribuyó a hacer más fuerte el ambiente de fraternidad con la causa. A lo largo del país, múltiples agrupaciones se identificaron con los patriotas y se organizaron para difundir su adhesión mediante actos públicos, como también para recaudar fondos en pro de los insurgentes. La prensa, en especial $L a$ Ley y La Nueva República, medios vinculados al Partido Radical el primero, y al liberal-balmacedismo el segundo, fueron los puntales en la difusión de esta labor.

Actores protagónicos en esta tarea fueron las agrupaciones populares, en especial la Confederación Obrera que, en junio de 1895, convocó a una asamblea y meeting con el objetivo de realizar peticiones al gobierno de la época para que coordinase acciones con otros gobiernos americanos en favor del respaldo a la causa de Cuba. La Confederación Obrera realizó también una amplia convocatoria de personalidades, partidos y organizaciones sociales a una "gran reunión para respaldar la acción de los patriotas cubanos, para el día 23 de junio" (La Ley, 19-VI-1895). Si bien la asistencia fue exitosa y heterogénea (La Ley, 27-VI-1895), su labor no concluyó ahí, designándose una comisión para hacer llegar al presidente de la República las conclusiones del mencionado acto. Aquella gran manifestación fue un acto de aliento a la causa cubana, pero también de impulso a todos aquellos que, como chilenos o caribeños, sentían esa tarea como la propia, como un imperativo moral, aún en la lejanía geográfica que, sin embargo, parecía que se acortaba en la proximidad de las ideas. A los días de haberse efectuado y con el fin de otorgarle una adecuada cobertura, La Ley (19-VI-1895), en su editorial, con un 
tono más reflexivo, se congratuló por la concurrencia y diversidad de los asistentes, siendo este acto la culminación de un proceso que se inició en febrero de 1895, la fraternidad del pueblo chileno para con la libertad en la isla, que fue resultado de una acción mancomunada y de claros objetivos.

La Ley fue un diario que manifestó en múltiples oportunidades su adhesión a la causa de la independencia de Cuba, señalando que el pueblo antillano "se levantará y soberano para ocupar el asiento que le corresponde en el gran banquete de la democracia americana" (La Ley, 04-V-1895) y, en referencia al acto convocado, pretendió destacar, en primer lugar, a la manifestación como una expresión de americanismo. Al respecto, relató que "Fue muy fuerte el aplauso, porque revela un fuerte sentimiento de americanismo que ha de redundar en beneficio de la confraternidad y de la respetabilidad exterior del continente" (La Ley, 27-VI-1895). Este diario se considera heredero de la gesta emancipadora que llevó a los pueblos de América a rebelarse contra el sometimiento extranjero, fundando su postura en uno de los elementos comunes en la identidad de nuestro continente. Para sus redactores, este sentimiento se reconoce como una centralidad dentro de sus convicciones "El derecho que no reconoce Patria, fue quien estableció la hermandad americana" (La Ley, 27-VI-1895). Esta postura fue planteada como un objetivo permanente, a propósito de la solidaridad con la independencia de Cuba, constituyéndose como una actitud ineludible, pues su objetivo no fue simplemente estrechar vínculos culturales, comerciales o políticos entre uno u otro país, sino que se trata de una representación y significado que aspiraba a "Unificar el alma en una específica coyuntura, pero que hace que la expresión de esa tarea sea más extensa en América” (La Ley, 27-VI-1895). Asimismo, a la distancia, llamó a no desesperar a los patriotas mientras persista el oprobio de la ocupación colonial, pues no serán pocos los medios que, como este, iniciarán una gran corriente de opinión contra los usurpadores. De igual manera, se congratuló por el meeting debido a la masiva asistencia de obreros y de estudiantes, hecho que, para La Ley, representa la generosidad más genuina del pueblo chileno que, con madurez, adhiere a causas nobles. Los asistentes representaban la confluencia de la razón y del corazón por una causa que consideraban como propia y, en consecuencia, agregó, "Esas dos fuerzas constituían el núcleo central de 
aquel concurrido meeting, en el cual formaron hermoso contraste el vivísimo fuego por la idea con la tranquila prudencia por las conclusiones" (La Ley, 27-VI-1895). En general, en diversas expresiones del texto periodístico se aprecia una cierta muestra de idealismo e incluso de ingenuidad. Llama la atención que el éxito no induzca a un lenguaje triunfalista y desafiante; por el contrario, son las razones, los argumentos, los que constituyen su principal forma de respaldo, no incitando los ánimos de revancha que fácilmente podrían explotar a la vista de tantas dificultades.

La Ley tomó distancia respecto de la autoridad política de la época, esperando que la presión que ejercía sobre el gobierno fuera una responsabilidad de las organizaciones sociales convocantes. Sin saber lo poco productivas que serían las gestiones de la comisión nombrada por los asistentes al meeting para hacer presentes al presidente de la República las conclusiones de acto, confiando, señaló, que "es una idea de que va en camino de la realidad” (La Ley, 28-VI-1895). A pesar de estas apreciaciones, fue evidente la existencia de una intensa disputa de representaciones, manifestada a través de las imágenes, soportes mediante los cuales la prensa local recreaba los sucesos bélicos en la isla. El optimismo que demostró la prensa afín al independentismo tuvo como contrapartida la elaboración de un discurso que buscó identificar, en el alzamiento, una dimensión de alarmante "guerra racial", intencionalidad que se escondía tras sus inspiradas e idealistas proclamas. En este cuadro, la influyente colonia hispana residente difundió informaciones destinadas a generar este significante, señalando que:

“En esta revuelta, los negros serían los que no por la razón, sino por la fuerza, se harán dueños absolutos; y una prueba palpable, que según publican los diarios separatistas y según manifiesta un defensor de ellos, que firma o se titula: 'Un Cubano', los revolucionarios ganaron una batalla a los españoles (...) y después del triunfo el jefe advirtió que entre ellos había un blanco e inmediatamente lo separaron" (El Noticiero Español, 04-V-1895).

Como podemos apreciar, esta información recoge una sutileza, ya que no fue la comisión de atroces actos de barbarie en la manigua, en contra de los vencidos, sino la determinación de los combatientes un gesto elocuente que anunciaba el pronto advenimiento de la inversión 
de jerarquía racial implantada por el dominio colonial, para establecer la supremacía, social y política de los afrocubanos. Por lo demás, estos eran un significativo contingente que, según algunas fuentes, constituía cerca de dos tercios de sus combatientes.

Contextualizado en el escenario nacional, El Noticiero Español aspiró a descalificar discursivamente a su contraparte, quizás buscando establecer un plano de similitud entre el supuesto carácter de la insurrección antillana y la adhesión de parte de las organizaciones populares como una amenaza sobre el orden social y los privilegios establecidos por este. De igual modo, esta arista levantada por la prensa de la colonia hispana poseía una especificidad y sofisticación mayor destinada al gobierno de la época, con el propósito de advertirle que no se involucrara en una rebelión protagonizada por violentas hordas de negros, siendo este un conflicto de carácter interno en el que no existía igual legitimidad entre los beligerantes. Esta dimensión racial, presente en la discursividad de los sectores proclives a la mantención del mandato colonial sobre la isla, se estableció de la misma manera con la intención de reforzar los vínculos de hermandad que unían a españoles y criollos. Esta estrategia retórica procede de una acción deliberada, cuyo fin fue establecer una brecha respecto de la posibilidad de la eventual influencia de los Estados Unidos en el Caribe.

Haciendo una verdadera apología del “buen colonizado", El Noticiero Español destaca no solo las bondades propias de los criollos, sino, sobre todo, su proximidad con el carácter de los peninsulares, hecho que, en la práctica, plantearía la excentricidad de todo proyecto emancipador, indicando que:

"El cubano no se ha sustraído, a las malas o buenas cualidades de origen latino; es cariñoso, apasionado, voluble y soñador, las vicisitudes y contingencias de la vida las que sufre con moderada resignación y es poco trabajador, etc., etc.."(El Noticiero Español, 06-VII1895).

Proviniendo de la misma fuente, las opiniones vertidas contrastan marcadamente respecto de la amenazante imagen que este medio propaga sobre los afrodescendientes que participan del alzamiento. En tal sentido, El Noticiario Español fue hábil en plantear su propio régimen de verdad respecto de la naturaleza de este conflicto, me- 
diante una dominación discursiva que actuó especialmente sobre sectores de la elite, induciendo a la mantención de neutralidad frente a las hostilidades.

La construcción de representaciones sociales negativas a través de sus páginas, logró desarticular entre sus lectores la imagen de reforma social sostenida por el PRC durante la guerra; la igualdad racial entre criollos y afrocubanos en la tropa, los ascensos a partir del mérito en combate y la promoción de los afrocubanos mediante su nombramiento como autoridades locales (Ferrer, 1999), se transformaron en los componentes de una trastocada iconografía en torno a una inexplicable rebelión de antiguos esclavos respaldada por un sector de la sociedad criolla. Este debate, lejos de concluir, se intensificó en el transcurso del año 1895, dando lugar a nuevas e intensas disputas.

\section{La visita de Arístides Agüero a Chile}

La llegada del delegado del Partido Revolucionario Cubano, Arístides Agüero' ${ }^{1}$ a Chile suscitó gran atención y representó un punto culminante de la demostración de fraternidad entre los pueblos chileno y cubano. Su presencia en el país obedecía a una política deliberada de la organización insurgente, con el fin de superar el aislamiento que su tarea había experimentado durante la campaña de 1874. La visita de Agüero estuvo precedida por una intensa campaña de difusión organizada por el comité creado especialmente para su gira, y que fue presidida por un directorio integrado por los señores Eugenio María de Hostos $^{2}$, Ramón Liborio Carvallo, Nicolás Tanco, Aníbal Labarca, Luis Camacho y Carlos Bull, quienes dividieron sus labores para dar cobertura y promover sus actividades en las ciudades que visitó.

Desde el primer momento del anuncio de su presencia de nuestro país comenzaron a aparecer, en diversos medios, informes sobre su visita, sobre todo en aquellos más afines a la causa de Cuba, como

1 Arístides Agüero, de profesión químico farmacéutico, fue nombrado delegado del Partido Revolucionario Cubano (PRC) y, en tal condición, visitó, durante 1895, Ecuador, Perú, Bolivia y Chile, para estimular las diversas iniciativas de adhesión y de solidaridad hacia el movimiento independentista en la isla, como asimismo para propiciar el reconocimiento oficial por parte de los gobiernos de la condición de beligerantes de los insurgentes (Gallegos, 2020).

2 Insigne intelectual del independentismo portorriqueño. En la época, rector del Liceo Miguel Luis Amunátegui, funcionario público. 
también detalles biográficos para mejor conocimiento de su persona. Desde luego, entre los convocantes, una amplia gama de organizaciones obreras, de socorros mutuos y filarmónica. ${ }^{3}$

Finalmente, luego de haber visitado Perú y de recibir el aprecio del pueblo limeño, inició, con su llegada a Iquique, su visita al país, para luego desembarcar en Valparaíso y por ferrocarril llegar a Santiago el domingo 6 de octubre de 1895, a la Estación Central. Según La Ley: "El recinto era estrecho para contener aquel mar de gente que ocupaba, además, formando masa compacta, una gran parte de la espaciosa plazuela" (La Ley, 8-X-1895). Opiniones coincidentes respecto de la concurrencia señalaron otros medios, como El Americano y El Mercurio de Valparaíso, constatando que el recibimiento del delegado fue todo un éxito y, como tal, era imposible omitirlo o restarle méritos. Este efecto se acrecentó, por cuanto Agüero era el primer cubano que visitaba el país como un activo miembro del PRC, habiéndose destacado en sus labores como tal en La Habana y Nueva York. El aparente impacto logrado por los organizadores, de mostrar la espontánea simpatía que el pueblo de Santiago le entregaba a su heroica visita, estaba destinado primordialmente a concitar mayor adhesión en los días venideros, para los actos que se realizarían en otras ciudades con el fin de recaudar fondos para mantener la lucha. Sumado a ello, interesaba de igual modo generar en el gobierno una sensación de incomodidad, tratando este de mantenerse al margen de toda forma de cortesía al visitante y hacia lo que él representaba.

La presencia de Agüero hizo más delgado el hilo por donde se equilibraba la incómoda política de prescindencia del gobierno frente a los hechos de Cuba, que determinaban sus compromisos de neutralidad.

3 Confederación Obrera, Protección de la Mujer, Fraternidad de Ambos Sexos, Unión de los Tipógrafos, Unión de Artesanos, Sociedad de Sastres, Filarmónica de Obreros, Inválidos de la guerra y Veteranos, Fermín Vivaceta de Carpinteros, Miguel Ángel de Pintores, Vicuña Mackenna de Cigarreros, Filarmónica José Miguel Infante, Unión Andrés Bello, Igualdad de Conductores de Carruajes, Musical de Socorros Mutuos, Artesanos del Progreso, Sociedad El Porvenir, Filarmónica Francisco Bilbao, Gremio de Abasto, Temperancia de Ambos Sexos, Logia Temperancia 21 de Mayo, Fraternal de Joyeros, Empleados de Farmacia, Empleados Peluqueros, Fomento de Ahorro Antonio Poupin, Maquinistas y Fogoneros de los Ferrocarriles del Estado, Igualdad y Trabajo, Manuel Rodríguez, Ahorros Amador Rodríguez, Ahorros Juan Gutenberg, Comerciantes del Mercado Central, Ahorros José Miguel Carrera, Filarmónica Unión, Cerrajeros y Herreros, Sociedad de Carroceros, Gasfiteros y Hojalateros, según La Ley, 5-X-1895. 
Los organizadores y, desde luego, el movimiento de los trabajadores que sustentaron la visita, demostraron habilidad a la hora de crear un hecho político, un incidente al que necesariamente la autoridad debía prestar atención. A la vez, se convirtió en un duro reto para la colonia y la representación diplomática española, puesto que su actuación se mostró en lo venidero extremadamente celosa en exigir que el Estado no diera ni la más mínima facilidad a los sectores pro independentistas y que ningún funcionario público participase de tales actos. Sin embargo, para el sector pro hispano la visita se convirtió en un riesgo que pudiese propiciar la simpatía y solidaridad del gobierno chileno hacia la causa de la isla.

Un caso que sirve de ejemplo, dice relación con los matices que se exponen a la hora de referirse a los eventuales frutos de esa visita, pero también de intento de desmitificar al visitante con epítetos como los que presenta el periódico de la colonia: "los chilenos ilustrados saben muy bien qué clase de gente es la que combate en la manigua y que aquella es una guerra racista y no una lucha de criollos por conseguir la independencia" (El Noticiero Español, 10-X-1895). Además de ello, se pretendió bajar el perfil al éxito logrado por el visitante con lo multitudinario de su visita, en directa alusión a La Nueva República que describió el acto como "multitudinario y conmovedor", saliendo al paso de tales declaraciones con ironía, señalando: "cualquiera al leer la descripción (...) creería que se trataba de la entrada del Héroe Prat en Valparaíso" (La Nueva República, 11-X-1895).

Más allá de la polémica en cuanto al real éxito alcanzado por Agüero en su llegada a Santiago, el periódico de la colonia hispana pretendió clarificar algunos aspectos que consideraba básicos ante situaciones de este tipo y que, como señalamos, pudiesen haber alterado el estado de las relaciones entre España y Chile. En primer lugar, aprovecha su influencia para recomendar al gobierno que debe mantener absoluta distancia frente a este tipo de encuentros, porque debe ser leal con los compromisos internacionales adquiridos y no puede respaldar actos en los que se profieren insultos contra un gobierno amigo, más todavía si de esos incidentes participan individuos que ejercen la función pública a título personal.

Este diario esgrimió una razón poderosa, considerando la coyuntura política interna. Buscando mayor comprensión en los gober- 
nantes, aludía a un tema delicado por esos años, al señalar que "el gobierno de Madrid no consentiría desplegar una bandera contraria al presidente Montt en caso de una manifestación hecha en las Cortes a un delegado balmacedista si sobreviniese una revolución" ( $E l$ Noticiero Español, 10-X-1895). Un argumento claramente sensible en ese contexto. Aparece también el argumento de que Agüero representa la violencia étnica, en una guerra que pretende convertirse en un estallido de terror racial, tal como otros ocurridos en otras islas del Caribe. Así, se señaló que "los yankees, reclutados en los EE.UU. i los negros i los mulatos de la isla que aspiran a convertir a Cuba en Haití y Santo Domingo" (El Noticiero Español, 10-X-1895), y veladamente, como si en el país fuese posible una situación de idéntica naturaleza, asimismo hacía mención de que los adherentes a la visita eran especialmente sectores obreros y que "las clases media y alta (...) brillaron por su ausencia" (El Noticiero Español, 10-X-1895). El Noticiero Español aclaró y confirmó con ello la gran identificación de los sectores obreros con los criollos cubanos, identificando a los adherentes como sectores poco influyentes, pues la elite no compartía, en sus palabras, esa simpatía. Tales afirmaciones nos aportan una clave para comprender el modo en que la demanda de soberanía de los cubanos insurrectos fue visualizada y entendida, en la realidad chilena del periodo, por parte de sectores obreros que la interpretaron como parte de una demanda por mayores espacios de participación, de derechos y de ciudadanía. Es importante destacar cómo la elite de la época pretendió, a través de sus medios de prensa, estigmatizar la causa de los rebeldes caribeños en función de su desconfianza y desinterés hacia los planteamientos de los sectores populares. El asumido ideario de carácter democrático-popular en el que trabajadores chilenos y los revolucionarios cubanos encontraron coincidencia fue observado como una abierta amenaza en contra de sus intereses. La intermediación de los hechos que hizo El Noticiero Español trasluce la doble desconfianza hacia el movimiento que se generó en Santiago, pues, por un lado, lo señala como inconveniente en un Estado que ha definido una política de neutralidad, pero, por sobre todo, plantea la alarma ante la peligrosa proximidad de los discursos de los patriotas cubanos y los obreros chilenos, cuestión obviamente peligrosa ante la eventualidad de protestas y manifestaciones derivadas del mal manejo que la autoridad pudiera hacer de esta situación. 
Por su parte, El Constitucional (12-X-1895) puso de relieve las ofensas que, en tales incidentes de recibimiento, se lanzaron contra la nación ibérica. Estas, a su juicio, eran totalmente torpes e innecesarias, pues, más que ayudar a Cuba, pudieron haber conducido a empeorar las excelentes relaciones de Chile con España. En ese mismo sentido, llama la atención de la prensa de la colonia hispana que su postura era en extremo legalista, puesto que sus objetivos no eran tanto ganar simpatías para su causa sino, más bien, controlar al gobierno. Conjuntamente, percibió con desconfianza a una expresión político-social crecientemente masiva y cuyo ideario posee componentes bien definidos, siendo capaz de trascender sus propias limitaciones para movilizarse en favor de otras causas como parte de una política de principios.

Además de estas visiones más polarizadas en la prensa hay otras un tanto más moderadas, como la que asume La Unión de Valparaíso, cuyas palabras son un tanto confusas, ya que no muestra grandes compromisos sino, más bien, una posición ecléctica: "sentimos que, a manifestaciones de este tipo, llamadas a herir las susceptibilidades de una nación amiga, se les quiere dar un carácter público o nacional" (La Unión, 11-X-1895). Pero, a la vez, otros medios reafirman su sentida adhesión por la causa que durante esos días representa en nuestro país el señor Agüero: “Como republicanos, no podemos sino mirar con simpatía el movimiento revolucionario de Cuba realizado para conseguir el triunfo de las ideas democráticas y de la libertad en la Isla" (El Americano, 06-X-1895). Una actitud claramente más definida la de este periódico, que no esconde su total adhesión a la causa de la libertad en las Antillas españolas, pues fue creado con tales objetivos. En sus ediciones del mes de octubre de ese año, un protagonista directo fue precisamente Arístides Agüero, informando con detalle de su arribo y congratulándose por su presencia en el país. Se entregan, además, sus datos biográficos, destacando muchas de sus cualidades y aptitudes. Este periódico asumió su presencia como un definitivo impulso al movimiento de solidaridad organizado, así como respecto de las importantes conquistas de este, señalando que "el Señor Agüero ha despertado espontáneo y sincero alborozo nacional" (El Americano, 06-X-1895). Lo que más tarde se reafirma, en un soneto que publica en su homenaje dicho medio: 
"La Santa causa de la Antilla hermosa

Que defiende su vida heroicamente

Encuentra en Chile un entusiasmo ardiente

Comunidad profunda y generosa"

(El Americano, 06-X-1895).

El optimismo que en sus notas editoriales expresa este periódico se entremezcla con noticias favorables sobre la insurrección, en las que se exaltan los méritos del ilustre visitante, quien "no solo hoy contribuye a la causa de Cuba sino lo hará cuando ésta sea libre, expulsando totalmente a los españoles". Del mismo modo, se refirió a las altas expectativas que el propio Agüero tenía sobre su presencia en Chile y sobre su misión en el país, entre otras, recaudar fondos para los elevados intereses que representa y que El Americano destacó al señalar que su presencia "inviste un carácter apostólico, pues nos trae la palabra que lejos de nosotros viven miles de hombres sumidos en la más vergonzosa esclavitud" (El Americano, 13-X-1895).

Coincidentemente con otros periódicos, El Americano describe el recibimiento en Santiago como un evento grandioso, haciendo mención de las palabras de los oradores y, en general, lo define como un gran encuentro de hermandad entre ambos pueblos, hecho que no se puede desconocer ni subestimar. Días más tarde, esta satisfacción fue opacada por las acciones del ministro de España en Chile, López Guijarro, quien, con el propósito de restringir los actos públicos de solidaridad ante la causa cubana, argumentó la neutralidad de Chile frente al conflicto, situación que para El Americano fue, más que incomprensible, una medida injusta, pues constituía "un anacronismo y un escandaloso atentado contra las libertades públicas querer poner una barrera de resistencia a los sentimientos que se han despertado (...) en aclamación al ilustre delegado de la Perla de las Antillas" ( $E l$ Americano, 31-X-1895).

Este medio aprovechó la oportunidad para señalar, con igual fuerza, su reconocimiento a la herencia hispánica de América, destacando el tono cordial con que se desarrollaron los incidentes y agregando que solo un grupo pequeño de los presentes profirieron insultos contra España, los cuales no fueron compartidos por el conjunto de los asistentes al acto. Esa animosidad contra España no solo se trataba de una reacción 
contra una nostálgica y decadente potencia colonial que había sido expulsada de otras regiones del continente. Más bien significaba, para los trabajadores, el ejemplo más concreto de un gobierno que, como el de Cánovas, hacía gala de la más arbitraria discriminación hacia los sectores populares, al imponer el sistema de los "soldados de reemplazo": jóvenes de origen humilde que, no habiendo podido pagar una elevada fianza para eximirse del reclutamiento, eran enviados a la guerra.

Este panorama explica la profunda distancia entre ambas tendencias de la prensa chilena, creándose un ambiente de polarización en el que no cabían posturas intermedias. Fue así como El Americano se congratuló públicamente de la postura que, gradualmente, asumió $L a$ Ley, al comprometerse con el independentismo, hecho importante toda vez que denotaba la posición al interior del Partido Radical, el que además repudió las medidas tomadas por el presidente Montt frente a las manifestaciones populares (El Americano, 31-X-1895). Luego de tales incidentes, el delegado cubano inició una gira hacia el sur, en ferrocarril. Su acogida fue tan plena de fraternidad y optimismo como la vista en Santiago. El independentismo debió afrontar las adversidades propias de su actitud desafiante ante los estertores del imperialismo español como hacia la política estadounidense, siempre a la expectativa del desarrollo del conflicto; no obstante, creemos que la fraternal recepción que la causa de Cuba tuvo en nuestro país fue un aliciente para proseguir con tal difícil tarea.

El optimismo inicial fue reemplazado por una actitud de cautela ante un gobierno neutral, pero que fue objeto de presiones diplomáticas extranjeras. Como balance, la prensa de la colonia hispana logró instalar su propia perspectiva sobre el conflicto. Los masivos actos de solidaridad popular hacia el independentismo no lograron ser un medio de presión efectiva sobre el ejecutivo, ni permitieron construir una relación de diálogo con este. Debemos destacar, de todas maneras, la solidaridad del propio Agüero hacia sus amigos chilenos, pues su ejemplo e incesante voluntad de difundir el sentido de su lucha constituyó un modelo que contribuyó a fortalecer la mística del movimiento social local, que recuperaba su capacidad de acción en los inicios de la República Parlamentaria.

Al mismo tiempo, empero, debemos reconocer la gran capacidad del movimiento obrero en la época, el que, junto a otras organizacio- 
nes, fue capaz de proyectar, a través de su labor, planteamientos que iban más allá de las convencionales reivindicaciones de carácter laboral, exponiendo una verdadera política de principios, desafiando la tibia actitud del gobierno y generando hechos de magnitud en un escenario claramente adverso.

\section{Reflexiones finales}

La revisión de las fuentes nos ha permitido vislumbrar la importancia social y política que adquirieron los asuntos relativos a la guerra de Independencia de Cuba, hacia 1895 en Chile. Llama la atención que la distancia geográfica no haya sido impedimento para la existencia de un acalorado debate público al respecto en la esfera nacional chilena, la que presentó diametrales posiciones de adhesión, especialmente en organizaciones populares, así como en aquellas correspondientes a la colonia hispana en el país. Observamos, por otra parte, la complejidad que ello representó para el gobierno de Jorge Montt y su posición de neutralidad frente a los sucesos antillanos. Dada la importancia que para la causa insurgente tenía la adopción de apoyo al levantamiento, el PRC definió la importancia que tenía la eventual ruptura de la posición prescindente frente al conflicto de parte de las autoridades de países como Ecuador, Perú y Chile, la que contribuiría a otorgarle a su postura una renovada visión anti-imperial española.

Las características de la política oligárquica y el escenario de creciente influencia de los Estados Unidos en la región, hizo que Chile adoptara una posición de suma prudencia y que privilegiara los acuerdos con países de influencia regional, como Brasil y Argentina, asumiendo, de igual modo, una postura de reticencia ante los intereses de Washington sobre el Caribe y de respeto ante los compromisos de mantención de neutralidad con el gobierno de España. Tal escenario logró configurar una condición de inmovilidad, junto a la de los demás estados de América Latina. Dicha condición, finalmente, le restó influencia a nivel regional e hizo de la posición definida por la autoridad un campo de permanente disputa que le generó más de alguna incomodidad. En este cuadro, ambos bandos, pro cubano y pro español, se valieron de cada desliz del gobierno que se alejara de la posición de neutralidad para denunciar el abandono de esta postura. En tal sentido, la visita del delegado del PRC Arístides Agüero representó una pro- 
vocación, al agudizar tal confrontación interna, reduciendo los márgenes de maniobra política del gobierno de Jorge Montt en Chile y en el extranjero. Lo anterior, no podría haber sido posible de no existir una de las plataformas fundamentales con las que contó el independentismo cubano en Chile, como fue el asociacionismo en el mundo de los trabajadores, que experimentaba una fase de ascenso tras la Huelga General de 1890.

Frente a lo anterior, la controversia en torno de los sucesos antillanos logró establecer una brecha al interior de los partidos políticos chilenos en la época, identificándose con claridad un ámbito de adhesión en la prensa ligada a los partidos Liberal-Democrático y Radical, efectivos interlocutores de las expresiones de solidaridad hacia el independentismo. La revisión de las fuentes nos ha permitido desprender la existencia de una interesante confrontación en el nivel de los discursos y una hábil articulación de estos en la mencionada coyuntura. De este modo, los trabajadores confraternizaron con una causa que, aunque distante, encarnaba los valores de libertad, justicia e igualdad que estos buscaban reivindicar, asumiendo la defensa de una causa que, anteriormente, el liberalismo había asumido en plenitud. Por su parte, los sectores de la colectividad española elaboraron y difundieron la imagen de una "guerra racial", movida por un deseo de venganza que solo buscaba extender el caos frente a la benevolencia del dominio colonial, planteando de algún modo un símil con la creciente autonomía de los sectores populares en Chile.

\section{Referencias bibliográficas}

Fuentes primarias

\section{a) Publicaciones periódicas}

El Americano, Santiago, 1895.

El Constitucional, Santiago, 1895.

La Ley, Santiago, 1895.

El Mercurio, Valparaíso, 1895.

El Noticiero Español, Santiago, 1895.

La Nueva República, Santiago, 1895.

La Unión, Valparaíso, 1895. 


\section{Fuentes secundarias}

\section{a) Artículos y capítulos de libros}

Ferrer, A. (1999). "Cuba, 1898: Rethinking race, nation an empire", en Radical History Review, $\mathrm{N}^{\circ} 73$, pp. 22-46.

Gallegos, C. A. (2020). "La Revolución cubana de 1895. El aporte de los viajes de Arístides Agüero a Perú, Chile y Bolivia”, en Revista Páginas, $\mathrm{N}^{\circ}$ 28, enero-abril, pp. 1-17.

González, C. y Martell-Gámez, L, (2013). "El análisis del discurso en la perspectiva foucaultiana: método y generación de conocimiento", en Revista Ra-Ximhai, Vol. 9, № 1, enero-abril, pp. 153-172.

Grez, T. S. (2000). “Transición en las formas de lucha: motines peónales y huelgas obreras en Chile (1891-1907)", en Historia, $\mathrm{N}^{\circ}$ 33, Pontificia Universidad Católica de Chile, Instituto de Historia, pp. 141-225.

López, R. (2015). "La solidaridad chilena con la primera guerra de independencia de Cuba: sus tensiones y contradicciones", en Revista de Historia y Geografía, N 32, Universidad Católica Silva Henríquez, pp. 53-76.

Guerra B., S. (1993). “La Revolución Independentista de Cuba y la Guerra de 1898 desde la perspectiva de América Latina", en Contrastes. Revista de Historia, $\mathrm{N}^{\text {os }}$ 7-8, pp. 63-80.

Pozo, J. M. (1998). “Relaciones chileno-cubanas (1848-1900)”, en Boletín de Historia y Geografía, No 14, pp. 343-356.

Soucy, D. (2009). "Les premiers partis politiques cubains et leur influence dans la constitution de l'Etat-nation (1878-1902)", en Amérique Latine Histoire et Mémoire. Les Cahiers $A L$ HIM. Consultado en https://journals.openedition.org/alhim/2889, el 10-I-2021.

Peyrou F. y D. Martykánová (2014). "Presentación dossier la historia transnacional", en Revista Ayer, $\mathrm{N}^{\circ}$ 94, pp. 13-22.

\section{b) Libros}

Ansaldi, W. y V. Giordano (2016). América Latina. La construcción del orden, Vol. I. Buenos Aires: Editorial Ariel.

Bethell, L. (Editor). (1992). Historia de América Latina, Vol. 9. Barcelona: Editorial Crítica. 
Carmagnani, M. (1984). Estado y sociedad en América Latina, 18501930. Barcelona: Editorial Crítica.

Castedo, L. (1999). Chile: vida y muerte de la república parlamentaria. Santiago, Chile: Editorial Sudamericana.

Collier S. y W. F. Sater (1999). Historia de Chile, 1808-1994. Madrid: Cambridge University Press.

Chartier, R. (1996). El mundo como representación. Barcelona: Editorial Crítica.

Garcés, M. (2002). Crisis y motines en el 1900. Santiago, Chile: Editorial Lom.

Hobsbawm, E. (2009). La era del Imperio, 1875-1914. Barcelona: Editorial Crítica.

Ramírez N., H. (2007). Obras Escogidas Vol. I Santiago, Chile: Editorial Lom.

Ramírez N., H. (2007). Balmaceda y la contrarrevolución de 1891. Santiago, Chile: Editorial Lom.

Salazar, G. y J. Pinto (1999). Historia Contemporánea de Chile. Santiago, Chile: Editorial Lom.

Subercaseaux, B. (1996). Historia de las ideas y de la cultura en Chile, Tomo II. Santiago, Chile: Editorial Universitaria. 